\title{
Industries, business cycle and profitability of momentum strategies:
}

\author{
An international perspective
}

Jean-François BACMANN ${ }^{1}$, Michel DUBOIS ${ }^{1}$, Dušan ISAKOV ${ }^{2}$

January 2001

\footnotetext{
${ }^{1}$ Institut de l'Entreprise, Université de Neuchâtel, Faubourg de l'Hôpital 77, 2000 Neuchâtel, Switzerland Phone: 41327181366 Fax: 41327181361

E-mail: jean-francois.bacmann@unine.ch e-mail: michel.dubois@unine.ch

${ }^{2}$ HEC-Université de Genève and International Center FAME, 40 Bd du Pont d'Arve, 1211 Genève 4, Switzerland

Phone: $41227058611 \quad$ Fax: 41227058104

E-mail: dusan.isakov@hec.unige.ch
} 


\title{
Industries, business cycle and profitability of momentum strategies:
}

\section{An international perspective}

\begin{abstract}
:
The apparent predictability of stock prices and the related profitability of investment strategies based on it has generated a great deal of research. Since the late eighties, momentum strategies have attracted a lot of the attention and have been found to be very profitable mainly for US stock market (NYSE and AMEX). A few papers (notable exceptions are Rouwenhorst (1998) and Chan, Hameed and Tong (2000)) have investigated this issue from an international perspective. In line with the recent literature this paper documents the profitability of momentum strategies in countries from the G-7 and explores some conjectures about the links existing between the return of these strategies, the business cycle and industries.
\end{abstract}

JEL classification: G11,G14,G15, E32 


\section{Industries, business cycle and profitability of momentum strategies: An international perspective.}

\section{Introduction}

The study of the predictability of stock returns has attracted a lot of attention from researchers even before the birth of financial theory (e. g. Cowles (1933)) and the development of the efficient market hypothesis by Fama (1970). Until the beginning of the eighties, members of academia were quite confident that it was impossible to properly anticipate the future fluctuation of stock prices and design any profitable trading rules from the observation of past prices. At that time the results of the numerous different tests were unanimous: these trading rules were clearly unprofitable. Since that time things have changed. Researchers have discovered a number of ways to predict future stock returns in a time-series setting. Rules drawn from technical analysis have been shown to provide profitable results as has been demonstrated by Brock, Lakonishok and LeBaron (1992). DeBondt and Thaler (1985) have investigated another pattern in stock prices that combine the time-series and cross-sectional settings. They have shown that so-called contrarian strategies are highly profitable. These strategies consist in ranking stocks according to their past 3 to 5-year performance and forming zero-cost portfolios that buy the loser stocks and short the winning stocks. When implemented on the US market, this strategy has been found to be quite profitable. The reverse strategy implemented on shorter horizon ( 3 to 24 months) has also been found to be profitable first by Lehmann (1990) and Jegadeesh and Titman (1993). This strategy, which was called relative strength rule by technicians, has been popularized by the name of momentum strategies in academic research.

Outside the US market, similar results are found on other stock markets as well; see Schiereck and Weber (1995) for the German market, Bacmann and Dubois (2000) for the Swiss Market, Hameed and Yuanto (2000) for six Asian markets and Mai (1995) for the French market. However, these papers do not cover the same period of time and the methodologies are not uniform. Two notable exceptions are Rouwenhorst (1998) who study the European stock markets and Chan, Hameed and Tong (2000) who focus their research on stock market indexes of twenty two countries. One of the goals of this paper is to extend internationally the 
evidence on the profitability of momentum strategies by analyzing stock markets of the countries member of the G-7. Moreover our paper gives some additional evidence on the ongoing debate on the source of the profitability of these strategies. It investigates their link with industries and the evolution of the business cycle in each of these countries.

The paper is organized as follows: the next section provides some selective literature review in the field of momentum strategies and section 3 describes the data. Section 4 presents the empirical results concerning the profitability of various momentum strategies for the G-7 countries. Section 5 examines the profitability of the same strategies conditional on the state of the business cycle. Section 6 suggests a new decomposition of the performance and section 7 concludes the paper.

\section{Previous research}

Lehmann (1990) and Lo and MacKinlay (1990) were the first to find that following a selffinancing investment strategy that recommends being long in recent losers and short in recent winners yields some profitable results on the short run (from one week to one month). These strategies are called "contrarian strategies". Their results were further expanded by Jegadeesh and Titman (1993) who found the opposite type of behaviour over the medium term horizon of 3 to 12 months. More precisely, they observed that momentum strategies (long in past winners and short in past losers) yield very profitable results. For horizons over 36-months a contrarian profit is again observed. As most of the evidence is obtained on the US markets it is important to ascertain whether this effect is present in other markets as well. These results were first confirmed from an international point of view by Rouwenhorst who also found profitable results for a 3- to 12-months horizons for more than 2100 individual stocks quoted on the 12 major European stock markets over the period 1978-1995. Similar results were obtained by Chan, Hameed and Tong (2000) for stock indices of 23 countries over the period 1980-1995. Momentum profits are still present although they are slightly less significant when applied to country indices.

As this profitability is persistent, it is important to understand its sources. One way to address this issue is to attribute the performance of such strategies to various factors. Lo and 
MacKinlay (1990) based their decomposition on the random walk hypothesis (i.e. the time series of stock returns is described with a random walk with drift under the null hypothesis) while Jegadeesh and Titman (1993) referred to the factor model. In both cases, the profits are decomposed in three different parts. The first one is linked to the cross-sectional dispersion in stock returns. The second one is due to the autocorrelation of returns and the third one is the residuals called the "over/underreaction component". The results from this decomposition are far from being unanimous. Based on the Lo and MacKinlay decomposition, Conrad and Kaul (1998) claimed that most of the performance of momentum strategies was due to the crosssectional dispersion in expected returns although Jegadeesh and Titman (2001) showed that it might not be the case ${ }^{3}$.

Another line of research has been to explicitly assume some irrationality by investors and that momentum may be driven by investor's underreaction to new information as conjectured by Jegadeesh and Titman (1993). There have been theoretical attempts to explain such behaviour as witnessed by the models of Barberis, Shleifer and Vishny (1998) and Daniel, Hirshleifer and Subrahmanyam (1998). Although several other conjectures about the source of the profitability of momentum strategies have been proposed ${ }^{4}$, none of them has really been able to give a convincing answer to the question, which still remains open.

Conrad, Cooper and Hameed (1999) showed that the momentum strategy is significantly influenced by the market condition: the profits of momentum strategies are substantially higher when the market is bullish. More specifically, the profits are due to the low profits to selling losers in up markets. Moskowitz (1999) documented conflicting results; he found momentum strategies to work best in recessions and when the market is doing poorly. These strategies are not profitable over the whole 1926-1994 period but that they are profitable since 1950; see Chordia and Shivakumar (2000). These authors were the first to highlight that momentum strategies are predominantly profitable in expansionary cycles of the US economy as dated by the National Bureau of Economic Research. The link between macroeconomic variables and momentum profits is important from a theoretical standpoint. In fact, asset

\footnotetext{
${ }^{3}$ A rational unconditional asset-pricing framework does not help in understanding the profitability of momentum strategies. The reason is that lagged factors are needed in order to explain momentum profits. The empirical evidence shows that factors like "size" and "book to market" do not exhibit such property (autocorrelation).

${ }^{4}$ Among others Chordia and Swaminathan (2000) investigate the issue of transaction costs and trading volume.
} 
pricing model like APT and ICAPM are mute concerning the factors driving stocks returns. Fama and French (1993) suggested that Book-to-Market and size are two candidates and Carhart (1997) added a third factor designed to capture the momentum effect. While Liew and Vassalou (1999) showed that the first two factors anticipate economic growth, they were unable to find such a relation for the momentum factor. Thus, the question is still open: is momentum a risk factor?

Recently, Moskowitz and Grinblatt (1999) showed that momentum profits are tightly linked to industries. More specifically, momentum profits in individual stocks disappear when controlled for industries. This result is challenged by Grundy and Martin (2001) who claim that it is not the case. They found momentum strategies based on stock-specific returns to be more profitable than those based on total returns. In their study, the profitability of a momentum strategy is not fully explained by the cross-sectional variability of expected returns or the risk exposure to a specific industry.

Our paper contributes to the ongoing debate by trying to give additional answers to the above mentioned questions. First it shows that momentum profits are present in most of the stock markets of the G-7 countries. Moreover it shows that these profits are related to industries as we investigate these strategies on indices from various industrial sectors. It also documents the relation of these profits with the business cycle of the various countries.

\section{Data description}

\subsection{Data}

This research analyses the profitability of momentum strategies in the countries of the G-7 (USA, Canada, Japan, UK, France, Germany, Italy). As our focus is on the role played by industries we use indices that represent the various industrial sectors over the period 19732000. More precisely we use monthly data from January 1, 1973 to December 31, 2000. These indices are Datastream Global Equity Indices and are obtained from Datastream International. They include dividends and are expressed in local currency. They follow the same classification as the indices provided by FTSE International. We use the most 
disaggregated indices (level 6 subsectors) in order to capture the widest scope of industries as possible. This amounts to a maximum of 87 sub-industries for the US stock market. As we will make some conjectures about the potential source of profitability of momentum strategies based on the fact that an industry is more or less cyclical, we use the definitions provided by Datastream/FTSE for services and consumer goods sectors. Moreover we add the following sectors as being cyclical: Mining, Oil \& Gas, Chemicals, Construction \& Building Materials, Forestry \& Paper, Steel \& Other Metals, Aerospace \& Defence, Electronic \& Electrical Equipment, Engineering \& Machinery and Real Estate ${ }^{5}$. Table 1 provides descriptive statistics for the cyclical and defensive industries.

\section{[Insert Table 1]}

The average monthly returns of cyclical industries is higher than the monthly returns of defensive industries for all the G-7 countries. Moreover the difference of returns (long in cyclical industries and short in defensive industries) is positive and significant (one sided t-test) with the notable exception of the Germany.

Finally, different sources are available to determine the phases, and more specifically the peaks and troughs, of the business cycles. The first to be mentioned is the US business cycle expansions and recessions provided by the National Bureau of Economic Research (NBER) which is the benchmark for the USA. However, as we are interested in studying G-7 countries, we need another indicator for the rest of the countries. We have used the cycle dating provided by the Organisation for Economic Cooperation and Development (OECD) ${ }^{6}$. The dates of the troughs and the peaks do not coincide exactly with the ones suggested by the NBER during the period for which the data overlap. Another related problem is that the OECD data are lacking for the end of the period. This is the reason why we decided to compute directly the peaks and the troughs from the Industrial Production index of each country of the G-7. This information was also collected from Datastream on a monthly basis.

\footnotetext{
${ }^{5}$ This classification seems to be quite arbitrary. However, it was suggested by analysts from different research department (CSFB, Deutsche Bank, Société Générale).

${ }^{6}$ For more details see the website of the OECD at http://www.ocde.org
} 


\subsection{Business Cycle Dating}

The determination and the duration of the cycle has received an enormous attention from macroeconomists. As our main goal is to study the return of momentum strategies, we do not discuss in great details the topic; the reader is referred to Kim and Nelson (1999) for recent econometric research on the topic. The method used in this paper is a standard one, developed by Hodrick and Prescott (1997).

Let $I P_{t, i}$ be the Industrial production of country $i$ during month $t$. The series are examined separately. Each one is decomposed into two components:

$$
I P_{t, i}=g_{t, i}+c_{t, i} \text { for } t=\{1, \cdots, T\}
$$

where $g_{t, i}$ is a growth component (trend) and $c_{t, i}$ is a cyclical component. To obtain a smooth estimation of the growth component, the following criterion is minimized:

$$
\underset{\left\{g_{t}\right\}}{\operatorname{Min}}\left\{\sum_{t=1}^{T} c_{t, i}^{2}+\lambda \sum_{t=1}^{T}\left[\left(g_{t}-g_{t-1}\right)-\left(g_{t-1}-g_{t-2}\right)\right]^{2}\right\} t \in\{1, \cdots T\}
$$

A standard value for the smoothing parameter with monthly data is $\lambda=14400$.

As suggested by Artis, Bladen-Hovell and Zhang (1998, p. 26), we determined the trough and peak for each country of the G-7 by applying the following algorithm to the series after having removed the trend:

- Peak and trough follow one another in succession

- The minimum length required between any two consecutive turning points (a phase) is 9 months

- The minimum length required between any two alternate turning points (a cycle of peak to peak or trough to trough) is 24 months

- The turning point is located at the extreme value in intervening phases. If more than one extreme value is found in one phase, the latest observation is chosen as the turning point

- An outlier (more than 3 standard deviation) will be ignored for the purpose of dating analysis unless the turning point subsequently defined is located immediately adjacent to that observation.

$D \exp _{t}$ is a dummy variable equal to 1 when the economy is into an expansion phase ( 0 into a recession phase). A peak (trough) is characterized as being the end of sequence of 1 (0). We 
call this method Hodrick and Prescott filtering (HPF). The turning points (peak and trough) for the G-7 countries are summarized in Table 2.

\section{[Insert Table 2]}

This method is somewhat descriptive as it does not allow for a specific test of being in a given phase of the cycle. More sophisticated techniques like switching regimes, first developed by Hamilton (1989), allow the researcher to obtain the probability of being in a phase. Their implementation is left for further research.

We find eight turning points for the US, Japan and Germany. This is exactly the same number of turning points referenced by the NBER (8) for the US. Moreover, the turning points obtained with this algorithm are close to the NBER reference dates. The correlation between NBER and HPF dummies is 0.54 and the correlation between OECD and HPF is 0.76 for the USA. We find six turning points for the UK, ten for Canada and twelve for France and Italy respectively. For the last two countries, the magnitude of the cycles is not pronounced during the eighties. We decided to take minor cycles into account. The results remain substantially the same when they are excluded.

\section{The Profitability of Momentum Strategies}

First, we replicate a set of strategies as previously implemented by Lehmann (1990), Lo and MacKinlay (1990) and Conrad and Kaul (1998) among others. The basic idea driving these strategies is to invest more in those indexes having extreme returns compared to the market as a whole. The strategies are applied within each market and the weights invested at time $t$ for the indexes in one country are as follows ${ }^{7}$ :

$$
w_{i, t-h}^{j}=\frac{1}{N_{t, j}}\left[R_{i, t-h}^{j}-R_{m, t-h}^{j}\right]
$$

\footnotetext{
${ }^{7}$ The amount invested in each index at time $t$ is referenced by the subscript $t$ - $h$ because we use information back to $t$ - $h$. the portfolio being constructed at time $t$.
} 
where $R_{i, t-h}^{j}$ are the returns of index $i$ of country $j$ and $R_{m, t-h}^{j}$, are the returns of an equally weighted portfolio of indexes based on all the indexes of country $j$ available during the period $[t-h ; t]$.

By construction, the weights sum to zero (zero cost portfolio). The profit of the strategy is :

$$
\pi_{t}^{j}=\sum_{i=1}^{N_{t}} w_{i, t-h}^{j} R_{i, t+h}^{j}
$$

where $\pi_{t}^{j}$ is the profit implied by the strategy and $R_{i, t+h}^{j}$ is the monthly returns of the index $i$ of country $j$ over the period $[t ; t+h]$.

In the standard strategy as defined above, the long position and the short position are timevarying. More precisely the positions are an increasing function of the dispersion of past returns. In order to keep constant the amount invested over time, each weight in the long and in the short side is normalized by the sum of the positive weights. The weights are modified as follows:

$$
\omega_{i, t-h}^{j}=\frac{w_{i, t-h}^{j}}{\sum_{i} w_{i, t-h}^{j+}}
$$

where $\sum_{i} w_{i, t-h}^{j+}$ is the sum of positive weights over the period $[t ; t+h]$.

We use six different holding periods $h$, where $h$ ranges from 3 months to 24 months. The weights are computed over the period $[t ; t+h]$. In Panel A (B) of Table 3 , the profits of the standard strategies (normalized strategies) are presented for the G-7 countries.

\section{[Insert Table 3]}

First, as documented previously by Grinblatt and Moskowitz (1999) for stock indexes, the profits of the strategies (standard and normalized) are positive at 6 months, 9 months, 12 months, 18 months and 24 months for the US. Rouwenhorst (1998) finds similar results for individual stocks of 12 European countries. Despite the fact that both studies are based on equally weighting the first decile of winners (long) and the last decile of losers (short), the general conclusion remains unchanged. The profits are not very sensitive to the way by which the weights are computed. For all the G-7 countries, the 6 months normalized strategy is 
positive and significant (at 5\%), the 9 months normalized strategy is also positive in six countries, Japan being an exception. The US are the only country for which the profits persist over 24 months.

\section{Cyclical and Defensive over the Business Cycle}

\subsection{Preliminary Results}

As we expect Cyclical and Defensive industries to perform differently over the Business Cycle, we define two equally weighted portfolios of cyclical indexes (Cyclical Portfolio) and of defensive indexes (Defensive Portfolio). The Cyclical Portfolio should outperform the Defensive Portfolio during the expansion periods while the reverse is expected during the recession periods. A first indirect confirmation of this conjecture comes from the results of Table 1 and 2. In these tables, we observe that cyclical sectors overperform defensive sectors and that expansion periods are more frequent than recession periods. Table 4 provides a formal test of this hypothesis.

\section{[Insert Table 4]}

In fact, our hypothesis is confirmed for Japan, France UK, Italy and Canada where Cyclical Portfolio performs better than Defensive Portfolio when the economy is in expansion. The evidence is mixed for the US as we do not to confirm our hypothesis. Nevertheless, the monthly average return of the zero-cost portfolio long in the Cyclical Portfolio and short in the Defensive Portfolio is positive but not significant at 5\% (the p-value is 6\%). Germany does not display this pattern, however we failed to find a profitable momentum strategy for this country.

\subsection{The Case of the US}

As the measure of the business cycles is subject to caution (i.e. our peaks and troughs are not determine with standard statistical tests), we want to compare the results obtained under 
different definitions of the business cycle. For that purpose, we use the standard NBER and OECD dates in conjunction with the HPF method previously described.

To test the significance of the returns of momentum strategies during the expansion phases, we regress the returns on two dummy variables indicating the state of the cycle:

$$
R_{h, t}^{U S}=a_{E} d \exp _{t}+a_{R} d \mathrm{rec}_{t}+\varepsilon_{h, t}^{U S A}
$$

where $R_{h, t}^{U S}$ is the return of the momentum strategy over the period $[t ; t+h]$ for the USA, $d \exp _{t}\left(d \operatorname{rec}_{t}\right)$ is a dummy variable equal to 1 when the economy is in expansion (recession) at time $t, a_{E}\left(a_{R}\right)$ is the average returns during an expansion (recession) and $\varepsilon_{h, t}^{j}$ is an error term. The returns computed over $h$ months overlap, thus the t-stats are corrected for autocorrelation and heteroscedasticity as suggested in Newey and West (1987). We also test the equality of the average returns over the phases (expansion and recession). The results of both tests are presented in Table 5 for the standard (Panel A) and normalized (Panel B) momentum strategies.

\section{[Insert Table 5]}

The results clearly show that the performance of the momentum strategies (standard and normalized) strongly depends on the state of the economy. For all holding periods, the returns are systematically higher during the expansion phase. During recessions, the results are mixed: we obtain frequently negative returns. However, when the holding period is long (18 or 24 months), the returns are positive albeit insignificant. The unique exception is when the cycle is measured with the OECD dates and there are some significant average returns for recession periods. The coefficient of the expansion dummy is statistically higher than the recession coefficient. These results clearly establish that the performance of momentum strategies highly depends on the state of the cycle. Note also that the HPF method provides higher returns under expansion phases. Moreover, we are able to construct a portfolio with higher returns which tell us that the signal is given at right time. In that sense, NBER and HPF are closely related while the OECD dating does not permit to find any significant difference between $a_{E}$ and $a_{R}$. In the next section, we extend the results for the G-7 countries. 


\subsection{Empirical Results for the G-7 Countries}

The various business cycles for the G-7 countries are established with the HPF method applied on industrial production. We compute the average returns for momentum strategies for expansion and recession periods. Table 6a presents the results for the standard momentum strategy.

\section{[Insert Table 6a]}

Four countries perfectly confirm our hypothesis of significant profitability of standard momentum strategies in expansion periods at all horizons considered: USA, France, UK and Canada. USA and Canada probably experience common economic conditions and have therefore relatively similar business cycle patterns. This is not the case for France and the UK which reinforces our findings. To a less extent, Germany belongs to this group of countries. In general, momentum are not significant for that country except for the 24 months horizon. This is precisely the horizon for which we find an asymmetric reaction of returns to the business cycle. The Italian case is more complicated in the sense that we find a momentum effect in both the recession and the expansion periods. This is probably due to the fact that we had some difficulties in identifying the phases of the cycle during the eighties and the nineties. This problem is not unique to our methodology as it is also mentioned by the OECD. Finally, Japan does not seem to respond to the same logic as the other countries and presents different results. As we do not find evidence of profitable momentum strategies in Japan (see Table 3), it is not surprising to have no difference between recession and expansion periods.

The results we have found in the previous section show that the dispersion of the returns is higher with the standard strategy and that for at least two countries the profitability is hidden by extreme positions. Now we turn our attention to the normalized momentum strategy which does not suffer such problem. Table $6 \mathrm{~b}$ presents the results for the normalized momentum strategy.

\section{[Insert Table 6b]}


Our main results are confirmed. Moreover, for countries such as Germany and Japan, we find that momentum are also asymmetric for 6 and 9 months strategies. In general, these results confirm our hypothesis of momentum strategies profitability stemming from expansion periods of the economy.

However these results imply further research in at least two directions. The first is the determination of the state of the business cycle, in particular for countries such as Japan and Italy which seem to behave very differently from the other ones. Industrial production may not be the best indicator to measure the evolution of the business cycle. Another direction that we want to pursue is to restrict our test periods to the sole ascending/descending phase of the cycle meaning that we want to exclude those months around the peaks/through. The way tests are actually performed around peaks for instance involves ranking stocks in ascending phase and holding them in a descending phase which may not be very accurate. Another direction worth investigating is to analyze the decompose the performance of the strategy depending on the state of the business cycle.

\section{A Conditional Analysis of the Performance}

\subsection{The model}

Currently there is a debate on the causes of the performance of the momentum strategies. Socalled heretics (for a detailed definition see Boudoukh, Richardson and Whitelaw (1994)) tend to attribute such results to the irrational behaviour of investors. For this school momentum strategies are a direct evidence that the market under-reacts to available information (i.e. past prices); see Barberis, Shleifer and Vishny (1998) among others. At the opposite, revisionists believe that the dispersion of returns is the main cause of the performance. In that case the profits of the strategy are a reward to risk and the anomaly disappears; see Conrad and Kaul (1998) under the hypothesis of a random walk (RWH) with drift. The main argument against the latter theory was exposed in Jegadeesh and Titman (2001). These authors showed that the profits of the momentum strategies are proportional to the holding period under the RWH. For example, if a 3 months strategy is maintained during the next 3 months, the profits are expected to double. The empirical evidence clearly rejects 
the hypothesis. However, as the dispersion of stock returns across industries is not constant over the business cycle, we know that the RWH is unsustainable. Chordia and Shivakumar (2000) analysed the performance with a conditional factor model and showed that the profits of momentum strategies are just a compensation for risk bearing. The predictability of stock returns is the consequence of the predictability of the risk premium. However, this approach strongly depends on the robustness of the benchmarks which is not warranted; see Bossaerts and Hillion (1998) and on the stability of the relation through time which is also not warranted; see Ghysels (1998).

We suggest a decomposition of the profits conditional on the state of the cycle in order to avoid this critical assumption. We assume that there are two states of the nature: recessions and expansions. Both states are exogeneously determined by the macroeconomic environment We consider that, in each state of the nature, monthly stock returns are described by a random walk with drift. In particular, the average monthly returns are not equal under recessions and expansions. This hypothesis is in accordance with our previous findings in Table 4 where we show that the Cyclical Portfolio and the Defensive Portfolio do not exhibit the same monthly average returns for the G-7 countries during 01-1973/01-2001.

Let us reconsider the Lo and MacKinlay (1990) decomposition. With our notations, the expected profit of the momentum strategy sharing same horizon $h$ (the subscript $h$ is omitted for convenience) as formation and holding period is:

$$
E\left(\pi_{t}\right)=E\left(\sum_{i=1}^{N} w_{i, t-h} R_{i, t}\right)
$$

At this point, two hypothesis are required to derive their decomposition:

- the universe of stocks is fixed for the whole period

- stock returns follow a random walk with a constant drift.

The first assumption induces a look ahead bias survival stocks at the end of the sample period are assumed to be known at the beginning of the period. A correction for this bias is suggested by Conrad and Kaul (1998). The second assumption is the crucial one in order to derive the mains results:

$$
E\left(\pi_{t}\right)=\sigma_{\mu}^{2}+E\left(P I_{t}\right)
$$


where $\sigma_{\mu}^{2}=\frac{1}{T-2} \sum_{t=2}^{T} \frac{1}{N} \sum_{i=1}^{N}\left(\mu_{i, t}-\bar{\mu}_{t}\right)^{2}$,

$$
E\left(P I_{t}\right)=\frac{1}{T-2} \sum_{t=2}^{T}\left(\frac{1}{N} \sum_{i=1}^{N}\left(R_{i, t} R_{i, t-1}-\mu_{i, t}^{2}\right)-R_{m, t} R_{m, t-1}+\bar{\mu}_{t}^{2}\right) .
$$

Our assumptions are different in that:

- we do not assume a fixed universe of stock

- monthly stock returns follow a switching regime depending on the state of the economy

- under each regime, stock returns follow a random walk with drift.

While conditional variance in stock returns is mostly driven by $\mathrm{ARCH}$ effects at the daily level, Hamilton and Susmel (1994) showed that ARCH effects disappear when the returns are computed monthly. In addition, a switching regime is still present at this frequency which is exactly what we assume. More formally, we have:

$$
\begin{aligned}
& R_{i, t}=\mu_{i, S_{t}}+\varepsilon_{i, S_{t}} \\
& \mu_{S_{t}}=\mu_{i, 1}\left(1-S_{t}\right)+\mu_{i, 2} S_{t} \\
& \varepsilon_{i, S_{t}} \sim N\left(0 ; \sigma_{i, S_{t}}^{2}\right)
\end{aligned}
$$

where $S_{t}$ is the state variable equal to 0 when the economy is in a recession and 1 otherwise. We can write the profit as:

$$
\begin{aligned}
\pi_{t} & =\sum_{i=1}^{N_{t}} w_{i, t-h} R_{i, t} \\
& =\sum_{i=1}^{N_{t}} w_{i, t-h}\left(\mu_{i, S_{t}}+\varepsilon_{i, S_{t}}\right) \\
& =\sum_{i=1}^{N_{t}} w_{i, t-h} \mu_{i, S_{t}}+\sum_{i=1}^{N_{t}} w_{i, t-h} \varepsilon_{i, S_{t}} \\
& =V_{t}+P I_{t}
\end{aligned}
$$

where $V_{t}$ is the variability of the cross-section of stock returns and $P I_{t}$ the modified profitability index. The expectation of the first term of equation (9) corresponds to the crosssectional variance of stock returns when there is one state (i.e. $S_{t}=1 \forall t$ ) and the number of assets is constant over time (i.e. $N_{t}=N \forall t$ ). The second term corresponds to the profitability index except that the variable can take different values depending on the state of the nature. Note that $V_{t}$ need not be positive for each $t$. 


\subsection{Empirical results}

Our main objective is to test if the profitability index is positive and significant and state dependent. For that purpose, we regress the profitability index on two dummy variables indicating the state of the cycle:

$$
P I_{h, t}^{j}=b_{E} d \exp _{t}+b_{R} d \mathrm{rec}_{t}+\varepsilon_{h, t}^{j}
$$

where $P I_{h, t}^{j}$ is the profitability index of the momentum strategy over the period $[t ; t+h]$ for country $j$.

A similar regression is estimated for the variability:

$$
V_{h, t}^{j}=c_{E} d \exp _{t}+c_{R} d \mathrm{rec}_{t}+\varepsilon_{h, t}^{j}
$$

where $V_{h, t}^{j}$ is the profitability index of the momentum strategy over the period $[t ; t+h]$ for country $j$.

In Table 7, we present the decomposition of the momentum strategies for each country and each horizon.

\section{[Insert Table 7]}

The main result of Table 7 is that the performance of the momentum strategies is explained by the dispersion of stock returns. The profitability index is never positive and significant. In some cases, especially for the 24 months strategy, the profitability index is negative and significant. However, even a contrarian strategy is not profitable because the variability is higher than the profitability index.

Another interesting result is that the variability of the strategy is high during the expansion periods while it is low during recessions. In particular, during the periods for which we find a the momentum strategies to be profitable. This result deserve a close examination and is left for further research.

\section{Conclusion}

This paper investigates the profitability of momentum strategies in international stock markets. The findings of the paper are the following. First it confirms that momentum strategies are profitable in the USA and more importantly in other countries from the G-7, warranting that it is not a country (US) specific phenomenon. It also confirms that the profitability of these strategies is linked to industries as we have worked with indices 
representing the various industrial sectors. We further investigate whether the profitability is linked to the evolution of the business cycle in respective countries. This is strongly confirmed by the data especially for USA, France, UK and Canada. Moreover, we find the profits of momentum strategies to be driven by the cross-sectional dispersion of stock indexes especially during expansion periods. Our the results found so far clearly call for more investigation to determine the origin of the dispersion of these strategies and to respond to the questions currently raised in this literature with our original dataset. 


\section{Table 1: Returns of Cyclical and Defensive 1/73-1/01}

Summary statistics of our industries are reported below including the total number of sectors (column 1) and the number of cyclical sectors (column 2) for each country. The average monthly returns of an equally weighted portfolio of cyclical indexes and defensive indexes are in column 3 and 4 respectively. The average monthly returns of a portfolio long in cyclical and short in defensives (column 5). All return estimates are multiplied by 100. Column 6 presents the t-stat for the null hypothesis of no excess return of cyclical against defensives. The critical value for in one-sided t-test is 1.64 at $5 \%$.

\begin{tabular}{lcccccc}
\hline & Nb of sectors & Nb of cyclical & Avg. RC & Avg. RD & Avg. RC-RD & t-stat \\
\hline USA & 87 & 49 & 0.778 & 0.634 & 0.144 & 1.79 \\
Japan & 81 & 50 & 0.531 & 0.380 & 0.151 & 1.64 \\
Germany & 62 & 36 & 0.573 & 0.531 & 0.041 & 0.51 \\
France & 62 & 41 & 1.234 & 0.499 & 0.735 & 3.91 \\
UK & 78 & 47 & 1036 & 0.618 & 0.417 & 2.89 \\
Italy & 47 & 29 & 0.983 & 0.632 & 0.350 & 2.31 \\
Canada & 66 & 39 & 0.802 & 0.564 & 0.238 & 2.00 \\
\hline
\end{tabular}




\section{Table 2: Business cycle Expansions and Contractions}

The turning points of the business cycle are computed by smoothing the Industrial Production Index for each country with the Hodrick and Prescott method. The transitory component $c_{t, i}$ (the residuals after having removed the trend) is used to detect the peaks and the troughs by applying the ALT algorithm as described in Artis and al. (1998). The peak is the last increasing value of the smoothed index.

\begin{tabular}{|c|c|c|c|c|c|c|c|c|c|c|c|c|c|}
\hline \multicolumn{2}{|c|}{ USA } & \multicolumn{2}{|c|}{ Japan } & \multicolumn{2}{|c|}{ Germany } & & \multicolumn{2}{|c|}{$\mathrm{UK}$} & \multicolumn{2}{|c|}{ Italy } & \multicolumn{2}{|c|}{ Canada } \\
\hline \multicolumn{14}{|c|}{ Panel A: Dates of the Peaks and the Troughs } \\
\hline Peak & Trough & Peak & Trough & Peak & Trough & Peak & Trough & Peak & Trough & Peak & Trough & Peak & Trough \\
\hline $11 / 73$ & & $2 / 74$ & & $8 / 73$ & & $8 / 74$ & & $6 / 73$ & & $6 / 74$ & & $3 / 74$ & \\
\hline & $3 / 75$ & & $3 / 75$ & & $7 / 75$ & & $5 / 75$ & & $8 / 75$ & & $9 / 75$ & & $5 / 75$ \\
\hline \multirow[t]{2}{*}{$12 / 78$} & & $2 / 80$ & & $12 / 79$ & & $9 / 76$ & & $6 / 79$ & & $1 / 77$ & & $8 / 79$ & \\
\hline & $12 / 82$ & & $19 / 82$ & & $11 / 82$ & & $12 / 77$ & & $5 / 81$ & & $3 / 78$ & & $10 / 82$ \\
\hline \multirow[t]{2}{*}{$6 / 84$} & & $10 / 84$ & & $11 / 85$ & & $8 / 79$ & & $8 / 89$ & & $3 / 80$ & & $7 / 84$ & \\
\hline & $9 / 86$ & & $5 / 87$ & & $1 / 87$ & & $8 / 82$ & & $5 / 92$ & & $8 / 83$ & & $11 / 86$ \\
\hline \multirow[t]{6}{*}{$4 / 89$} & & $6 / 91$ & & $6 / 91$ & & $3 / 85$ & & & & $12 / 89$ & & $5 / 88$ & \\
\hline & $3 / 91$ & & 7/93 & & $7 / 93$ & & $1 / 87$ & & & & $1 / 94$ & & $2 / 91$ \\
\hline & & & & & & $1 / 90$ & & & & $12 / 94$ & & $1 / 95$ & \\
\hline & & & & & & & $8 / 93$ & & & & $12 / 96$ & & 7/98 \\
\hline & & & & & & $11 / 94$ & & & & $10 / 97$ & & & \\
\hline & & & & & & & $3 / 97$ & & & & $5 / 99$ & & \\
\hline \multicolumn{14}{|c|}{ Panel B : Number of periods under Expansion and Recession } \\
\hline Exp & $\operatorname{Rec}$ & Exp & Rec & Exp & $\operatorname{Rec}$ & Exp & $\operatorname{Rec}$ & Exp & $\operatorname{Rec}$ & Exp & Rec & Exp & $\mathrm{Rec}$ \\
\hline 219 & 118 & 205 & 132 & 248 & 89 & 148 & 189 & 252 & 85 & 169 & 168 & 177 & 160 \\
\hline
\end{tabular}




\section{Table 3: Average profits to trading strategies for different horizons}

The weights invested at time $t$ for the standard strategy: $w_{i, t-h}^{j}=\frac{1}{N_{t, j}}\left[R_{i, t-h}^{j}-R_{m, t-h}^{j}\right]$ where $R_{i, t-h}^{j}$ are the returns of index $i$ in country $j$ and $R_{m, t-h}^{j}$, are the returns of an equally weighted portfolio of indexes based on all the indexes of country $j$ available during the period $[t-h ; t]$; the weights for the normalized strategy are modified as follows: $\omega_{i, t-h}^{j}=\frac{w_{i, t-h}^{j}}{\sum_{i} w_{i, t-h}^{j+}}$ where $\sum_{i} w_{i, t-h}^{j+}$ is the sum of positive weights over the period $[t-h ; t]$. The profit implied by the strategy are: $\pi_{t}^{j}=\sum_{i=1}^{N_{t}} w_{i, t-h}^{j} R_{i, t+h}^{j}$ where $R_{i, t+h}^{j}$ is the monthly returns of the index $i$ of country $j$ over the period $[t ; t+h]$.

\begin{tabular}{|c|c|c|c|c|c|c|}
\hline \multicolumn{7}{|c|}{ Panel A: Standard Strategy } \\
\hline & 3 months & 6 months & 9 months & 12 months & 18 months & 24 months \\
\hline \multirow[t]{2}{*}{ USA } & 0.054 & $0.502 *$ & $1.487 *$ & $1.964 *$ & $1.806^{*}$ & $2.536^{*}$ \\
\hline & 1.33 & 2.75 & 2.86 & 2.73 & 2.24 & 2.37 \\
\hline \multirow[t]{2}{*}{ Japan } & 0.127 & 0.876 & 2.124 & 2.409 & -0.497 & $-1.661 *$ \\
\hline & 1.27 & 1.50 & 1.35 & 1.18 & -1.12 & -2.60 \\
\hline \multirow[t]{2}{*}{ Germany } & 0.265 & 0.962 & 2.529 & 2.947 & 0.056 & $3.234 *$ \\
\hline & 1.75 & 1.73 & 1.68 & 1.68 & 0.04 & 3.08 \\
\hline \multirow[t]{2}{*}{ France } & 0.063 & $0.400 *$ & $0.985^{*}$ & $1.174 *$ & -0.131 & $-2.739 *$ \\
\hline & 1.36 & 2.92 & 3.45 & 2.81 & -0.17 & -2.21 \\
\hline \multirow[t]{2}{*}{ UK } & $0.137^{*}$ & 0.361 & $1.556^{*}$ & $2.128 *$ & -0.277 & -2.099 \\
\hline & 2.01 & 1.65 & 2.00 & 2.19 & -0.19 & -0.82 \\
\hline \multirow[t]{2}{*}{ Italy } & $0.179 *$ & $0.778 *$ & $1.529 *$ & $1.749 *$ & -0.979 & $-6.214 *$ \\
\hline & 3.87 & 3.77 & 4.03 & 3.03 & -0.85 & -2.06 \\
\hline \multirow[t]{2}{*}{ Canada } & 0.066 & $0.465^{*}$ & $0.917 *$ & $0.840^{*}$ & 0.735 & 0.221 \\
\hline & 1.22 & 3.09 & 3.00 & 2.09 & 1.02 & 0.23 \\
\hline
\end{tabular}

A * indicates that the average return is significantly different from zero (with Newey-West correction) at a 5\% level. All profit estimates are multiplied by 100. 
Table 3 (continue): Average profits to trading strategies for different horizons

Panel B: Normalized Strategy (1 currency unit long minus 1 currency unit short)

\begin{tabular}{lcccccc}
\hline USA & 0.016 & $0.093^{*}$ & $0.191^{*}$ & $0.204^{*}$ & $0.172^{*}$ & $0.162^{*}$ \\
Japan & 1.73 & 3.21 & 3.39 & 3.42 & 2.85 & 2.32 \\
& 0.030 & $0.104^{*}$ & 0.207 & 0.281 & -0.045 & $-0.118^{*}$ \\
Germany & 1.60 & 2.18 & 1.79 & 1.35 & -0.98 & -2.34 \\
& $0.070^{*}$ & $0.168^{*}$ & $0.301^{*}$ & $0.273^{*}$ & 0.172 & $0.429 *$ \\
France & 2.21 & 3.74 & 3.72 & 3.49 & 1.76 & 3.62 \\
& $0.044^{*}$ & $0.138^{*}$ & $0.251^{*}$ & $0.216^{*}$ & 0.007 & -0.161 \\
UK & 2.34 & 3.16 & 3.91 & 2.65 & 0.06 & -1.06 \\
& $0.047 *$ & $0.094^{*}$ & $0.224^{*}$ & $0.250^{*}$ & 0.036 & -0.023 \\
Italy & 2.64 & 2.43 & 2.35 & 2.46 & 0.35 & -0.16 \\
& $0.129 *$ & $0.297 *$ & $0.464 *$ & $0.519 *$ & 0.112 & -0.502 \\
Canada & 5.14 & 4.20 & 5.07 & 3.63 & 0.48 & -1.02 \\
& 0.004 & $0.083^{*}$ & $0.126^{*}$ & 0.081 & 0.018 & -0.018 \\
& 0.17 & 2.03 & 2.28 & 1.21 & 0.19 & -0.14
\end{tabular}

$\mathrm{A} *$ indicates that the average return is significantly different from zero (with Newey-West correction) at a 5\% level. All profit estimates are multiplied by 100. 
Table 4: Returns of Cyclical and Defensive over the Business Cycle 1/73-1/01

An index is considered as a security. We form an equally weighted portfolio of cyclical indexes and of defensive indexes within a country. In column 1 and 2 (column 3 and 4), the average returns of Cyclical (Defensive) under recession and expansion phases of the cycle are presented for each country. In column 5 and 6 , we show the average monthly returns of a portfolio long in Cyclical and short in Defensive.

\begin{tabular}{lcccccc}
\hline & \multicolumn{2}{c}{ Cyclical } & \multicolumn{2}{c}{ Defensive } & \multicolumn{2}{c}{ Cyclical - Defensive } \\
& Recession & Expansion & Recession & Expansion & Recession & Expansion \\
\hline USA & 0.572 & 0.817 & 0.403 & 0.678 & 0.170 & 0.139 \\
Japan & 1.31 & 4.28 & 1.41 & 5.42 & 0.85 & 1.58 \\
& 0.055 & 0.663 & 0.100 & 0.458 & -0.045 & 0.206 \\
Germany & 0.14 & 3.27 & 0.43 & 3.75 & -0.23 & 1.98 \\
& 0.323 & 0.656 & 0.291 & 0.612 & 0.032 & 0.044 \\
France & 1.07 & 3.76 & 1.39 & 5.06 & 0.19 & 0.47 \\
\multirow{2}{*}{ UK } & 0.744 & 1.373 & 0.315 & 0.550 & 0.429 & 0.822 \\
& 1.34 & 4.66 & 1.60 & 5.25 & 1.07 & 3.86 \\
Italy & 0.745 & 1.121 & 0.464 & 0.663 & 0.281 & 0.457 \\
& 1.50 & 4.18 & 2.00 & 5.29 & 0.92 & 2.78 \\
Canada & 0.224 & 1.168 & 0.216 & 0.734 & 0.008 & 0.434 \\
& 0.37 & 3.87 & 0.66 & 4.55 & 0.02 & 2.56 \\
\hline The & 0.327 & 0.932 & 0.324 & 0.630 & 0.004 & 0.302 \\
& 0.84 & 4.55 & 1.69 & 6.29 & 0.02 & 2.25 \\
\hline
\end{tabular}

The critical value at 5\% is 1.96 . All profit estimates are multiplied by 100 . 


\section{Table 5: Returns of momentum strategies over the Business Cycle for the USA 1/73-1/01}

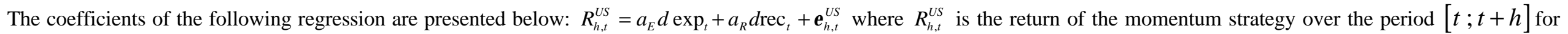

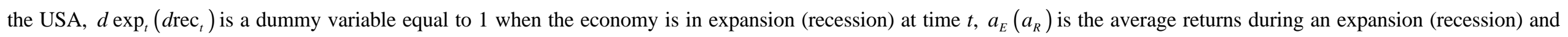

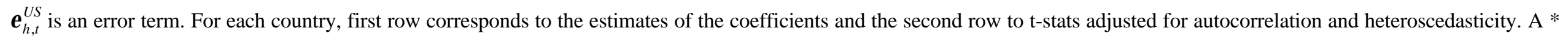
indicates that the coefficients $a_{E, j} \geq a_{R, j}$ at $5 \%$ (one sided t-test).

\begin{tabular}{|c|c|c|c|c|c|c|c|c|c|c|c|c|}
\hline & \multicolumn{2}{|c|}{3 months } & \multicolumn{2}{|c|}{6 months } & \multicolumn{2}{|c|}{9 months } & \multicolumn{2}{|c|}{12 months } & \multicolumn{2}{|c|}{18 months } & \multicolumn{2}{|c|}{24 months } \\
\hline & Recession & Expansion & Recession & Expansion & Recession & Expansion & Recession & Expansion & Recession & Expansion & Recession & Expansior \\
\hline \multicolumn{13}{|c|}{ Panel A: Standard strategy } \\
\hline \multirow[t]{2}{*}{$\begin{array}{l}\text { NBER } \\
\text { NBE }\end{array}$} & -0.123 & 0.083 & -0.131 & $0.606^{*}$ & 0.264 & $1.693 *$ & 0.126 & $2.265^{*}$ & 0.178 & $2.041 *$ & -0.024 & $2.855^{*}$ \\
\hline & -1.29 & 1.90 & -0.53 & 2.96 & 0.59 & 2.84 & 0.24 & 2.75 & 0.14 & 2.27 & -0.02 & 2.42 \\
\hline OCDE & -0.014 & 0.090 & 0.248 & $0.637 *$ & 0.853 & $1.835^{*}$ & 1.170 & $2.395 *$ & 1.744 & 1.839 & 1.743 & $2.943^{*}$ \\
\hline \multirow[t]{2}{*}{$\mathrm{HPF}$} & -0.108 & 0.086 & -0.042 & $0.611^{*}$ & 0.421 & $1.705^{*}$ & 0.291 & $2.313^{*}$ & -0.208 & $2.197 *$ & -0.748 & $3.11 * 0$ \\
\hline & -1.24 & 1.95 & -0.19 & 2.90 & 0.99 & 2.78 & 0.58 & 2.71 & -0.18 & 2.38 & -0.54 & 2.58 \\
\hline \multicolumn{13}{|c|}{ Panel B: Normalized strategy (1 UC long - 1 UC short) } \\
\hline \multirow[t]{2}{*}{$\overline{\text { NBER }}$} & -0.021 & $0.022 *$ & -0.020 & $0.112 *$ & 0.022 & $0.219 *$ & -0.012 & $0.240 *$ & -0.046 & $0.203^{*}$ & -0.058 & $0.189^{*}$ \\
\hline & -0.94 & 2.20 & -0.37 & 3.53 & 0.29 & 3.46 & -0.16 & 3.59 & -0.32 & 3.16 & -0.59 & 2.48 \\
\hline \multirow[t]{2}{*}{ OCDE } & 0.002 & 0.024 & 0.059 & $0.111 *$ & 0.129 & $0.225^{*}$ & 0.145 & $0.236^{*}$ & 0.140 & $0.188^{*}$ & 0.094 & $0.197 *$ \\
\hline & 0.16 & 1.89 & 1.88 & 2.73 & 2.83 & 2.72 & 2.44 & 2.77 & 1.60 & 2.39 & 1.14 & 2.14 \\
\hline \multirow[t]{2}{*}{ HPF } & -0.017 & 0.023 & 0.002 & 0.111 & 0.047 & 0.220 & 0.020 & 0.243 & -0.041 & 0.213 & -0.073 & 0.203 \\
\hline & -0.86 & 2.22 & 0.04 & 3.42 & 0.68 & 3.37 & 0.28 & 3.51 & -0.35 & 3.23 & -0.86 & 2.58 \\
\hline
\end{tabular}




\section{Table 6a: Average returns of standard momentum strategies conditioned on the Business Cycle 1/73-1/01}

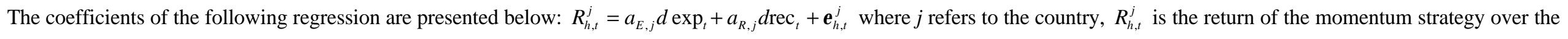

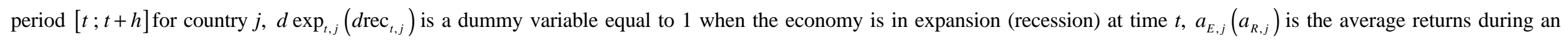

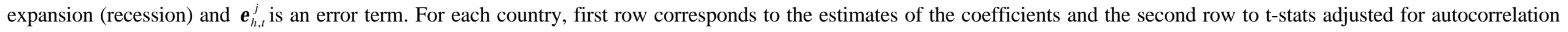
and heteroscedasticity. A * indicates that the coefficients $a_{E, j} \geq a_{R, j}$ at $5 \%$ (one sided t-test).

\begin{tabular}{|c|c|c|c|c|c|c|c|c|c|c|c|c|}
\hline & \multicolumn{2}{|c|}{3 months } & \multicolumn{2}{|c|}{6 months } & \multicolumn{2}{|c|}{9 months } & \multicolumn{2}{|c|}{12 months } & \multicolumn{2}{|c|}{18 months } & \multicolumn{2}{|c|}{24 months } \\
\hline & Recession & Expansion & Recession & Expansion & Recession & Expansion & Recession & Expansion & Recession & Expansion & Recession & Expansior \\
\hline \multirow[t]{2}{*}{ USA } & -0.108 & $0.086^{*}$ & -0.042 & $0.611 *$ & 0.421 & $1.705^{*}$ & 0.291 & $2.313^{*}$ & -0.208 & $2.197 *$ & -0.748 & $3.110^{*}$ \\
\hline & -1.24 & 1.95 & -0.19 & 2.90 & 0.99 & 2.78 & 0.58 & 2.71 & -0.18 & 2.38 & -0.54 & 2.58 \\
\hline \multirow[t]{2}{*}{ Japan } & 0.017 & 0.158 & 0.062 & 1.112 & 0.870 & 2.496 & 1.353 & 2.730 & -0.661 & -0.450 & -0.788 & -1.894 \\
\hline & 0.34 & 1.27 & 0.56 & 1.48 & 1.18 & 1.25 & 0.87 & 1.14 & -1.78 & -0.81 & -1.51 & -2.40 \\
\hline Germany & 0.72 & 1.72 & 0.76 & 1.72 & 0.74 & 1.67 & -0.16 & 1.71 & -0.63 & 0.09 & 1.80 & 2.89 \\
\hline \multirow[t]{2}{*}{ France } & -0.061 & 0.098 & 0.027 & $0.511^{*}$ & 0.351 & $1.176^{*}$ & 0.193 & $1.478^{*}$ & -0.946 & 0.134 & -3.728 & -2.435 \\
\hline & -0.86 & 1.80 & 0.18 & 3.04 & 1.12 & 3.34 & 0.38 & 2.93 & -1.37 & 0.14 & -3.11 & -1.55 \\
\hline \multirow[t]{2}{*}{ UK } & 0.109 & 0.145 & -0.044 & 0.485 & 0.042 & $2.030 *$ & -0.203 & $2.876^{*}$ & -6.741 & $1.756^{*}$ & -15.981 & $2.010^{*}$ \\
\hline & 1.19 & 1.75 & -0.24 & 1.75 & 0.20 & 2.02 & -0.65 & 2.29 & -1.89 & 1.24 & -2.30 & 0.91 \\
\hline Italy & 2.16 & 3.33 & 2.16 & 3.33 & 3.63 & 3.74 & -0.20 & 3.32 & -1.56 & 0.09 & -2.29 & -0.98 \\
\hline \multirow[t]{2}{*}{ Canada } & -0.043 & 0.096 & 0.547 & 0.442 & 1.000 & 0.892 & 0.206 & 1.029 & -2.665 & $1.804 *$ & -6.392 & $2.256^{*}$ \\
\hline & -0.23 & 2.16 & 1.11 & 3.49 & 1.09 & 3.22 & 0.19 & 2.60 & -2.36 & 2.27 & -3.72 & 2.48 \\
\hline
\end{tabular}

$\mathrm{A} *$ indicates that the coefficients are statistically different at $5 \%$. 
Table 6b: Average returns of normalized momentum strategies over the Business Cycle 1/73-1/01 (1 UC long- 1 UC short)

\begin{tabular}{|c|c|c|c|c|c|c|c|c|c|c|c|c|}
\hline & \multicolumn{2}{|c|}{3 months } & \multicolumn{2}{|c|}{6 months } & \multicolumn{2}{|c|}{9 months } & \multicolumn{2}{|c|}{12 months } & \multicolumn{2}{|c|}{18 months } & \multicolumn{2}{|c|}{24 months } \\
\hline & Recession & Expansion & Recession & Expansion & Recession & Expansion & Recession & Expansion & Recession & Expansion & Recession & Expansior \\
\hline \multirow[t]{2}{*}{$\overline{\mathrm{USA}}$} & -0.017 & $0.023^{*}$ & 0.002 & $0.111^{*}$ & 0.047 & $0.220^{*}$ & 0.020 & $0.243^{*}$ & -0.041 & $0.213^{*}$ & -0.073 & $0.203^{*}$ \\
\hline & -0.86 & 2.22 & 0.04 & 3.42 & 0.68 & 3.37 & 0.28 & 3.51 & -0.35 & 3.23 & -0.86 & 2.58 \\
\hline \multirow[t]{2}{*}{ Japan } & 0.008 & 0.036 & 0.007 & $0.133^{*}$ & 0.149 & 0.225 & 0.181 & 0.311 & -0.123 & -0.023 & -0.117 & -0.118 \\
\hline & 0.42 & 1.62 & 0.22 & 2.20 & 1.04 & 1.68 & 0.75 & 1.40 & -2.11 & -0.42 & -1.97 & -1.93 \\
\hline \multirow[t]{2}{*}{ Germany } & 0.026 & 0.085 & 0.035 & $0.215^{*}$ & 0.064 & $0.386^{*}$ & 0.002 & $0.371^{*}$ & -0.061 & 0.252 & 0.360 & 0.452 \\
\hline & 0.96 & 2.07 & 0.86 & 3.75 & 0.81 & 3.77 & 0.02 & 4.13 & -0.38 & 2.19 & 1.97 & 3.16 \\
\hline \multirow[t]{2}{*}{ France } & -0.011 & 0.060 & -0.004 & $0.180^{*}$ & 0.078 & $0.303^{*}$ & -0.012 & $0.287 *$ & -0.205 & 0.076 & -0.502 & $-0.056^{*}$ \\
\hline & -0.26 & 2.95 & -0.06 & 3.54 & 0.69 & 4.17 & -0.08 & 3.17 & -1.45 & 0.57 & -2.65 & -0.30 \\
\hline \multirow[t]{2}{*}{ UK } & 0.029 & 0.053 & -0.021 & $0.129^{*}$ & -0.004 & $0.296^{*}$ & -0.024 & $0.339^{*}$ & -0.365 & $0.162^{*}$ & -0.667 & $0.168^{*}$ \\
\hline & 0.86 & 2.57 & -0.35 & 2.83 & -0.08 & 2.42 & -0.55 & 2.59 & -2.66 & 1.34 & -2.61 & 1.07 \\
\hline \multirow[t]{2}{*}{ Italy } & 0.154 & 0.123 & 0.226 & 0.315 & 0.289 & 0.509 & 0.205 & 0.604 & -0.355 & 0.243 & -1.234 & -0.285 \\
\hline & 2.66 & 4.48 & 3.02 & 3.64 & 3.41 & 4.53 & 1.34 & 3.47 & -0.93 & 0.89 & -2.01 & -0.47 \\
\hline \multirow[t]{2}{*}{ Canada } & -0.053 & 0.020 & 0.057 & 0.090 & 0.066 & 0.143 & -0.127 & 0.143 & -0.578 & $0.206^{*}$ & -0.913 & $0.258 *$ \\
\hline & -0.60 & 0.91 & 0.49 & 2.32 & 0.43 & 2.72 & -0.74 & 2.25 & -2.80 & 2.38 & -3.33 & 2.24 \\
\hline
\end{tabular}




\section{Table 7: Performance of momentum strategies over the Business Cycle 1/73-1/01}

The coefficients of the following regression are presented below: $P I_{h, t}^{j}=b_{E} d \exp _{t}+b_{R} d \mathrm{rec}_{t}+\varepsilon_{h, t}^{j}$ where $P I_{h, t}^{j}$ is the profitability index of the momentum strategy over the period $[t ; t+h]$ for country $j$. A similar regression is estimated for the variability: $V_{h, t}^{j}=c_{E} d \exp _{t}+c_{R} d \mathrm{rec}_{t}+\varepsilon_{h, t}^{j}$ where $V_{h, t}^{j}$ is the profitability index of the momentum strategy over the period $[t ; t+h]$ for country $j, d \exp _{t, j}\left(d \mathrm{rec}_{t, j}\right)$ is a dummy variable equal to 1 when the economy is in expansion (recession) at time $t$, the regression coefficients are the average value of the variable during an expansion (recession) and $\varepsilon_{h, t}^{j}$ is an error term. For each country, first row corresponds to the estimates of the coefficients and the second row to t-stats adjusted for autocorrelation and heteroscedasticity.

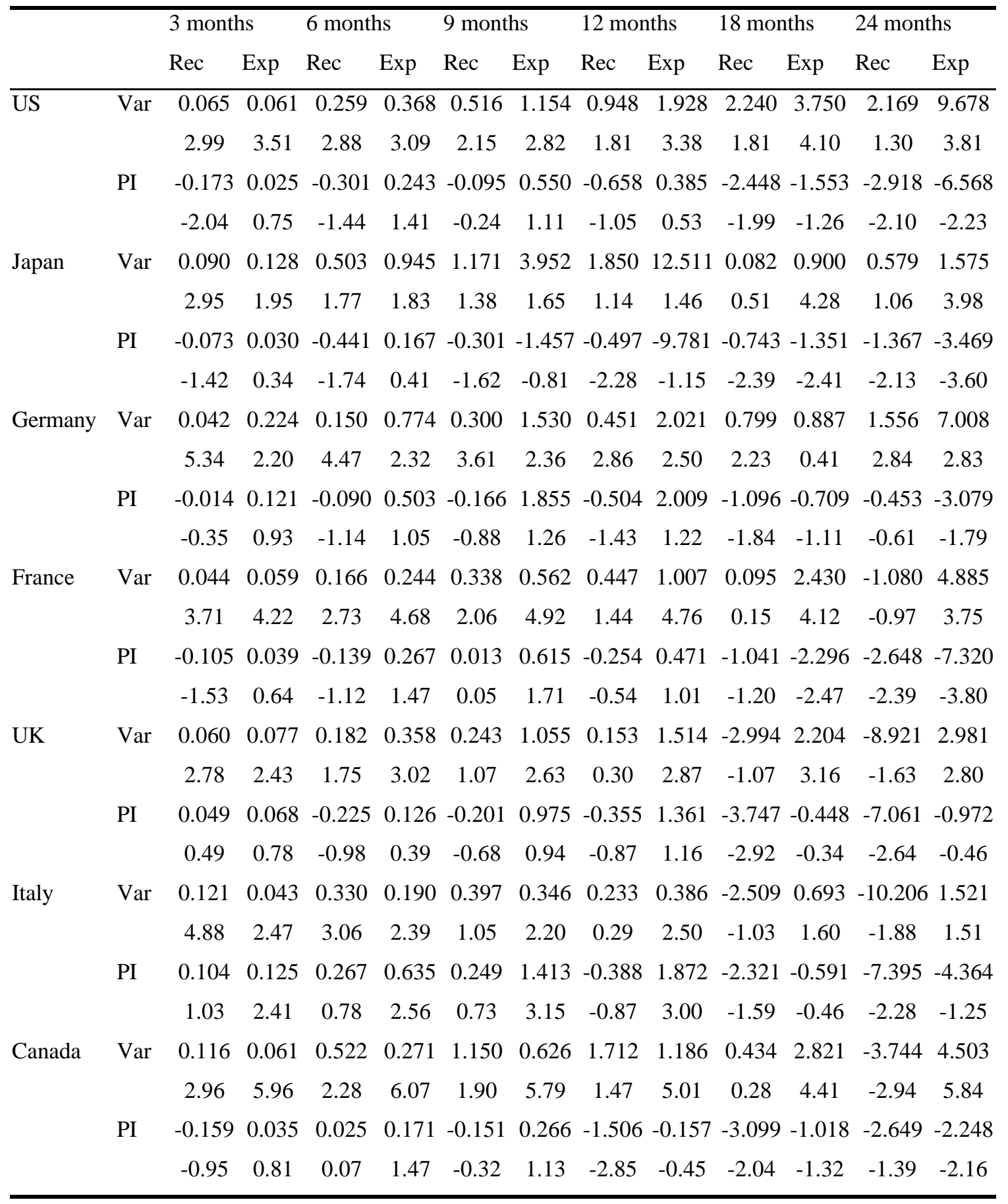




\section{References}

Artis M., Bladen-Hovell R. and W. Zhang, 1998, Turning points in the international business cycle: an analysis of the OECD leading indicators for the G-7 countries, http://www.ocde.org/std/li.htm

Bacmann J.F. and Dubois M., 2000, La performance des stratégies contraires et momentum sur le marché suisse, Finanzmarkt und Portfolio Management 14.

Barberis N., Shleifer A. and Vishny R., 1998, A model of investor sentiment, Journal of Financial Economics 49, 307-343.

Bossaerts P. and Hillion P, 1998, Implementing statistical criteria to select return forecasting models: What do we learn, Review of Financial Studies 12, 405-428

Boudoukh J., Richardson M. and Whitelaw R., 1994, A tale of three schools: A reexamination of autocorrelation patterns in stock returns, Review of Financial Studies 7, 539-573.

Brock W., Lakonishok J. and LeBaron B., 1992, Simple technical trading rules and the stochastic properties of stock returns, Journal of Finance 47, 1731-1764.

Carhart M., 1997, On persistence in mutual fund performance, Journal of Finance 52, 57-82.

Chan K., Hameed A. and Tong W., 2000, Profitability of momentum strategies in the international equity markets, Journal of Financial and Quantitative Analysis 35, 153172.

Chordia T. and Shivakumar L, 2000, Momentum, business cycle and time-varying expected returns, Working Paper, Emory University and London Business School.

Chordia T. and Swaminathan B., 2000, Trading volume and cross-autocorrelations in stock returns, Journal of Finance 55, 913-935.

Conrad J. and Kaul G., 1998, An anatomy of trading strategies, Review of Financial Studies $11,489-520$. 
Conrad J., Cooper M. and A. Hameed, 1999, Asymmetric price momemtum and market conditions, Working Paper, University of North Carolina at Chapel Hill.

Cowles A., 1933, Can stock market forecasters forecast?, Econometrica 1, 309-324.

Daniel K., Hirshleifer D. and Subrahmanyam A., 1998, Investor psychology and security market under- and overreactions, Journal of Finance 53, 1839-1886.

DeBondt W. and Thaler R., 1985, Does the stock market overreact?, Journal of Finance 40, 793-805.

Fama E., 1970, Efficient capital markets: A review of theory and empirical work, Journal of Finance 25, 383-417.

Fama E. and French K., 1993, Common risk factors in the returns on stocks and bonds, Journal of Financial Economics 53, 427-465.

Grundy B. and Martin S., 2001, Understanding the nature of the risks and the source of the rewards to momentum investing, Review of Financial Studies 14, 29-78.

Ghysels E., 1998, On stable factor structures in the pricing of risk: Do time-varying betas help or hurt?, Journal of Finance 53, 549-574.

Hameed A. and Yuanto K., 2000, Momentum strategies: Evidence form the Pacific Basin stock markets, http://www.ssrn.com

Hamilton J., 1989, A new approach to the economic analysis of nonstationary time series and the business cycle, Econometrica 57, 39-70.

Hamilton J. and R. Susmel, 1994, Autoregressive Conditional Heteroskedasticity and Changes in Regime, Journal of Econometrics 45, 307-333. 
Hodrick R. and E. Prescott, 1997, Postwar U.S. Business Cycles: An Empirical Investigation, Journal of Money Credit and Banking 29, 1-16.

Jegadeesh N., and Titman S., 1993, Returns to buying winners and selling losers: Implications for stock market efficiency, Journal of Finance 48, 65-91.

Jegadeesh N., and Titman S., 2001, Profitability of momentum strategies: An evaluation of alternative explanations, Journal of Finance, forthcoming.

Kim C. and C. Nelson, 1999, State-space Models with Regime Switching. Cambridge: MIT Press.

Lehmann B., 1990, Fads, martingales and market efficiency, Quarterly Journal of Economics $105,1-28$

Liew J. and Vassalou M., 1999, Can Book-to market, size and momentum be risk factors that predict economic growth, Journal of Financial Economics, forthcoming.

Lo A. and MacKinlay C., 1990, When are contrarian profits due to stock market overreaction?, Review of Financial Studies 3, 175-205

Mai, H. M., 1995. Sur-réaction sur le marché français des actions au Règlement Mensuel 1977-1990, Finance 16, 113-136.

Moskowitz T., 1999, An analysis of risk and pricing anomalies, http://www.ssrn.com

Moskowitz T. and Grinblatt M., 1999, Do industries explain momentum?, Journal of Finance $54,1249-1290$.

Newey W. and K. West, 1987, A simple positive semi-definite, heteroskedasticity and autocorrelation consistent covariance matrix, Econometrica 55, 703-708.

Rouwenhorst G., 1998, International momentum strategies, Journal of Finance 53, 267-284. 
Schiereck D. and Weber M., 1995, Zyklische und antizyklische handelsstrategien am deutschen aktienmarkt, in Meyer M.: Der overreaction-effekt am deutschen aktienmarkt, 3-24. 